\title{
Anesthetic and pathological changes following high doses of ketamine and xylazine in Sprague Dawley rats
}

\author{
Marie-Chantal GIROUX ${ }^{1)}$, Pierre HÉLIE ${ }^{2)}$, Patrick BURNS ${ }^{3)}$, and Pascal VACHON ${ }^{1,4)}$ \\ 1) Faculty of Veterinary Medicine, Departments of Veterinary Biomedicine, University of Montreal, 3200 rue Sicotte, \\ Saint-Hyacinthe, Quebec, J2S 2M2, Canada \\ ${ }^{2)}$ Faculty of Veterinary Medicine, Departments of Pathology and Microbiology, University of Montreal, \\ Saint-Hyacinthe, Quebec, Canada \\ 3) Faculty of Veterinary Medicine, Departments of Veterinary Clinical Sciences, University of Montreal, \\ Saint-Hyacinthe, Quebec, Canada \\ 4) Sainte-Justine University Hospital Research Center, Montreal, Canada
}

\begin{abstract}
The main objective of this study was to compare the effects of ketamine and xylazine in aging rats when coadministered intraperitoneally at high anesthetic doses. Three groups ( $n=6$ rats/ group) consisting of rats at 3, 6 and 12 months of age were used. During anesthesia, animals were monitored for heart rate, respiratory frequency, blood oxygen saturation, and rectal temperature. The corneal and paw withdrawal reflex were also examined during anesthesia. During anesthesia, withdrawal and corneal reflexes were absent for progressively longer durations with increasing age. Significant decreases in cardiac and respiratory frequency and, blood oxygen saturation occurred for the 6- and 12-month-old animals. Respiratory frequency and blood oxygen saturation returned to normal at the end of the anesthesia; however, the significant decrease in cardiac frequency persisted in the 6- and 12-month-old animals. Rectal temperature was decreased significantly only in the 3-month-old animals. Pulmonary edema and effusion occurred in $50 \%$ of the 12 -month-old animals. In conclusion, if ketamine-xylazine are used for anesthesia, the doses should be optimized for the age of the subjects prior to initiation of the research project.
\end{abstract}

Key words: aging, anesthesia, ketamine, rats, xylazine

\section{Introduction}

Ketamine and xylazine are commonly used in combination for the anesthesia of rodents [12-14, 25]. Ketamine is a glutamate N-Methyl-D-Aspartate (NMDA) antagonist that causes dissociative anesthesia and analgesia [40]. Opioid [30] and $\mathrm{GABA}_{\mathrm{A}}$ [37] receptors are also sites of action for ketamine, which may be associated with its sedative and analgesic properties. Xylazine is an $\alpha 2$-adrenergic agonist with analgesic, sedative and muscle-relaxant properties [15, 27]. Ketamine-xylazine
$(\mathrm{KX})$ are given together by different routes of administration, including intraperitoneally [5, 7], providing a surgical anesthesia plane and pain relief in rats. Anesthetic doses administered vary greatly in the literature with the doses being 40 to $260 \mathrm{mg} / \mathrm{kg}$ for ketamine and 5 to $39 \mathrm{mg} / \mathrm{kg}$ for xylazine when given intramuscularly, and 75 to $100 \mathrm{mg} / \mathrm{kg}$ for ketamine and $10 \mathrm{mg} / \mathrm{kg}$ for xylazine respectively when given intraperitoneally [11]. However, KX very often does not provide a surgical level of anesthesia in mice, and adding acepromazine to the mixture greatly increases its efficacy $[5,7]$.

(Received 18 October 2014 / Accepted 20 January 2015 / Published online in J-STAGE 27 March 2015)

Address corresponding: P. Vachon, Department of Veterinary Biomedicine, Faculty of Veterinary Medicine, University of Montreal, 3200 rue

Sicotte, Saint-Hyacinthe, Quebec, J2S 2M2, Canada

(C)2015 Japanese Association for Laboratory Animal Science 
The main reported negative side effects of $\mathrm{KX}$ are cardiac depression, bradycardia, and hypotension [7]. Both drugs cause respiratory depression, and the effects can be additive [34]. These negative side effects are mediated by central and peripheral adrenoeceptors and, muscarinic and NMDA receptors [4, 15, 28]. High doses of xylazine have been shown to cause pulmonary edema, and they may cause death in rats [1-3]. In a previous publication [36], we looked at the pharmacokinetics of ketamine and xylazine in young ( 2 months) and old ( $>2$ years of age) Sprague Dawley rats using a high dose of ketamine $(125 \mathrm{mg} / \mathrm{kg})$ and xylazine $(10 \mathrm{mg} / \mathrm{kg})$, but we did not evaluate physiological changes during anesthesia, and few organs were collected for histopathology. In old animals, we found that the elimination half-lifes of both ketamine and xylazine were greatly increased, suggesting decreased metabolism of these drugs with aging. Liver and kidney histopathology showed no significant changes related to anesthesia, however the lungs and hearts were not subjected to histopathology. Older animals have decreased liver function, which translates into a decrease in hepatic microsomal enzyme activity that could explain the significant increase in half-lifes of the drugs. This was proposed as an explanation for prolonged xylazine-ketamine anesthesia, which may have deleterious effects as animals get older [1]. However, the progressive modifications of hepatic metabolism with aging have not been shown in relation to rodent anesthesia. A progressively shorter duration of anesthesia has been shown in rats from 1 to 3 weeks of age, with the duration of anesthesia stabilizing at 4 to 12 weeks of age. This was shown to be correlated to hepatic metabolism [38]. No KX anesthesia studies have been performed in rats of different ages ranging from 3 months to 2 years of age to see if any physiological or pathological responses occur with aging. The objective of this study was therefore to compare the depth of anesthesia and histological changes following a recommended high dose of ketamine and xylazine in Sprague Dawley rats of different ages ranging from 3 to 12 months.

\section{Materials and Methods}

\section{Subjects}

Eighteen male specific pathogen free rats Sprague Dawley (Crl:CD (SD)) originating from Charles River (St-Constant, QC, Canada) were used for this study.
Two- and 3-month-old rats ( $\mathrm{n}=6$ /age group) were purchased and kept until they were respectively 3 and 6 months old. Eight-month-old retired breeder rats were purchased and kept until they were $1 \mathrm{yr}$ of age. At the time of experimentation, 3, 6 and 12 month rats weighed respectively $482 \pm 17 \mathrm{~g}, 638 \pm 57.5 \mathrm{~g}$, and $767 \pm 64.2 \mathrm{~g}$. All rats were housed in a standard laboratory animal environment (fresh filtered air, 15 changes/h; temperature, $21 \pm 2^{\circ} \mathrm{C}$; humidity, $50 \pm 20 \%$; and light-dark cycle, $12: 12 \mathrm{~h}$ ). The rats were housed individually in ventilated cages (Green Line IVC Sealsafe Plus, Tecniplast, West Chester, PA, USA) on corn cob bedding (7097 Corncob, Harlan Teklad, Bartonville, IL, USA) changed once a week. One high-temperature polycarbonate rat retreat (Bio-serv, Flemington, NJ, USA) and one Nylabone (chew toy from Bioserv, Flemington, NJ, USA) were placed in each cage for environmental enrichment. The rats received tap water and a certified laboratory diet (2018 Teklad Global 18\% Protein Rodent Diet, Harlan Teklad, Bartonville, IL, USA) ad libitum. The experimental protocol was approved by the Institutional Animal Care and Use Committee of the Ste-Justine Hospital Research Center in accordance with the guidelines of the Canadian Council on Animal Care [8].

\section{Treatments}

All rats received intraperitoneally $125 \mathrm{mg} / \mathrm{kg}$ of ketamine (Ketalean, Bimeda-MTC, Cambridge, ON, Canada) and $10 \mathrm{mg} / \mathrm{kg}$ of xylazine (Xylamax, Bimeda-MTC, Cambridge, ON, Canada). These doses were selected from a previous study on the effects of ketamine and xylazine in aging animals [36].

\section{Evaluation of anesthesia depth}

Following the KX injection, different parameters were evaluated at selected time points $(5,15,30$ and $45 \mathrm{~min}$, $1 \mathrm{~h}$, and every half hour thereafter) until a paw withdrawal reflex was observed. Rectal temperature was monitored (Thermalert TH-8, Physitemp, Clifton, NJ, USA) and a small animal oximeter (CANL-425V, Med Associates, St. Alban, VT, USA) was used for monitoring cardiac frequency and blood oxygen saturation by taping the sensor to the right hind paw. Respiratory frequency was monitored by direct observation (over $1 \mathrm{~min}$ ). The corneal reflex (always evaluated by MCG) was evaluated by gently pressing on the cornea with a cotton tip covered with a non-medicated ophthalmic gel.

The anesthesia duration was evaluated as the period 


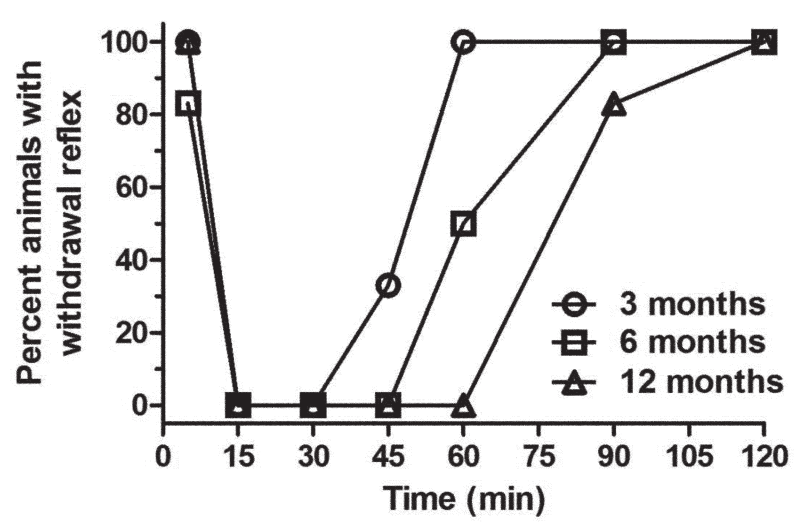

Fig. 1. Percent of Sprague Dawley rats ( $n=6 /$ group: 3,6 , and 12 months old) showing a positive withdrawal reflex when evaluated at selected time points $(5,15,30$, and $45 \mathrm{~min}$, and $1,1.5$, and $2 \mathrm{~h}$ ) following intraperitoneal administration of $125 \mathrm{mg} / \mathrm{kg}$ of ketamine and $10 \mathrm{mg} / \mathrm{kg}$ xylazine.

from loss to recovery of the paw withdrawal reflex (always evaluated by MCG), which was evaluated by pressing interdigital hind paw skin with hemostatic forceps in a manner that would not cause tissue damage. The recovery time was measured as the time until the first voluntary movement following the KX injection.

\section{Statistical analysis}

An analysis of variance (ANOVA) linear model with repeated measures was performed with SAS (version 9.3, SAS Institute Inc., Cary, NC, USA) to evaluate the effect of time (within group variance) for rectal temperature, heart rate, respiratory frequency, and oxygen saturation. To compare the age effect, an ANOVA linear model with repeated measures was used, and a priori contrasts were done to compare the means of each group with an adjustment of alpha with a Bonferroni sequential correction. Groups were compared for 15, 30, and $45 \mathrm{~min}$ results, since all animals showed no withdrawal reflex at these time points.

The statistical significance level was set a priori at $P<0.05$. Data in the article and figures are reported as means $( \pm \mathrm{SE})$.

\section{Results}

The withdrawal reflex (WR) results (Fig. 1) show a clear difference in anesthesia duration between different age groups following the administration of KX. The WR was absent in the 3-, 6-, and 12-month-old animals for

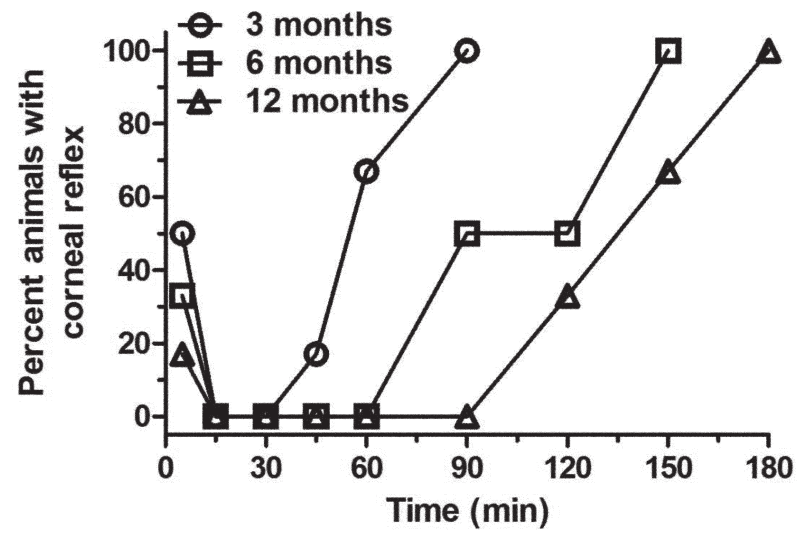

Fig. 2. Percent of Sprague Dawley rats ( $n=6 /$ group: 3,6 , and 12 months old) showing a positive corneal reflex when evaluated at selected time points $(5,15,30$, and $45 \mathrm{~min}$, and $1,1.5$, and $2 \mathrm{~h}$ ) following intraperitoneal administration of $125 \mathrm{mg} / \mathrm{kg}$ of ketamine and $10 \mathrm{mg} / \mathrm{kg}$ xylazine.

15,30 , and 45 min respectively, and all animals recovered at 60,90 , and $120 \mathrm{~min}$ respectively. The most apparent changes were seen at 60 min with all the 3-monthold rats recuperating by that time and the WR absent in the 12-month-old rats. The corneal reflex (Fig. 2) followed the same pattern: the reflex was absent from 15 to 60,15 to 90 and 15 to $120 \mathrm{~min}$ and fully recovered at 90,150 , and $180 \mathrm{~min}$ in the 3-, 6-, and 12-month-old rats respectively. The most apparent changes were seen at $60 \mathrm{~min}$, where there is a clear difference between the 3 month old rats and older animals, and at 90 min with a clear difference between the 3- and 12-month-old rats. First voluntary movements were noted at $85.6 \pm 23.3$, $123.4 \pm 40.0$, and $150.5 \pm 24.5 \mathrm{~min}$ for the 3 -, 6 -, and 12 -month-old rats respectively. The results for the 6 - and 12 -month-old rats were significantly different from those of the 3 month-old-rats $(P<0.05$ and $P<0.001$, respectively).

Heart rate did not vary with time for the 3-month-old animals $\left(\mathrm{F}_{4,20}=2.35, P=0.09\right)$, but did vary for the 6$\left(\mathrm{F}_{5,25}=10.57, P<0.0001\right)$ and 12 -month-old rats $\left(\mathrm{F}_{6,29}=7.13, P<0.0001\right)$. The 6- and 12-month-old rats had a significantly decreased heart rate (Fig. 3) that did not return to normal at the end of anesthesia. Significant age group differences were found between the 3-monthold group and older animals $(P<0.01$ at 30 and $45 \mathrm{~min}$ ).

Respiratory frequency (Fig. 4) varied with time for the 3- $\left(\mathrm{F}_{4,20}=5.33, P<0.005\right), 6-,\left(\mathrm{F}_{5,25}=3.29, P<0.03\right)$ and 12-month-old rats $\left(\mathrm{F}_{6,29}=16.2, P<0.0001\right)$. All groups had a significantly decreased respiratory frequency at 


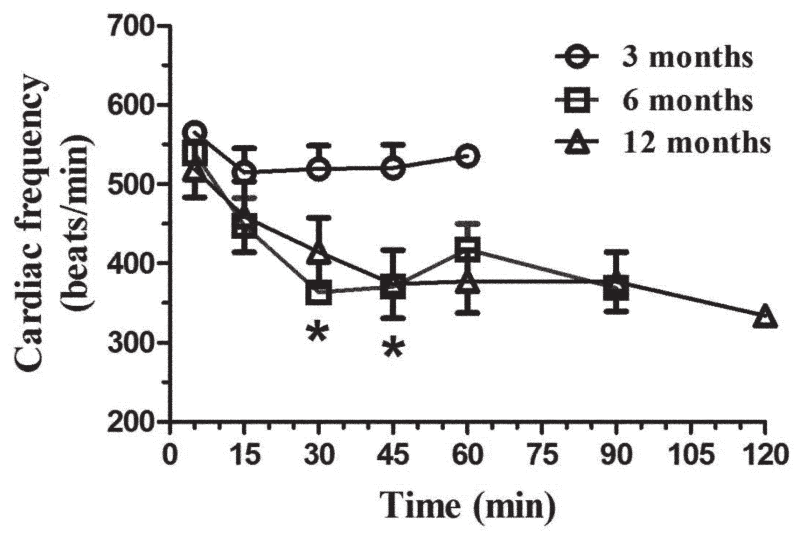

Fig. 3. Mean $( \pm \mathrm{SE})$ heart rate (beats/min) in Sprague Dawley rats (n=6/age group: 3,6 , and 12 months old) following intraperitoneal administration of $125 \mathrm{mg} / \mathrm{kg}$ of ketamine and $10 \mathrm{mg} / \mathrm{kg}$ xylazine. The heart rate was evaluated with a pulse oximeter at selected time points $(5,15,30$, and $45 \mathrm{~min}$, and $1,1.5$, and $2 \mathrm{~h}$ ), with the evaluations ending when animals had a positive withdrawal reflex. $* P<0.01$.

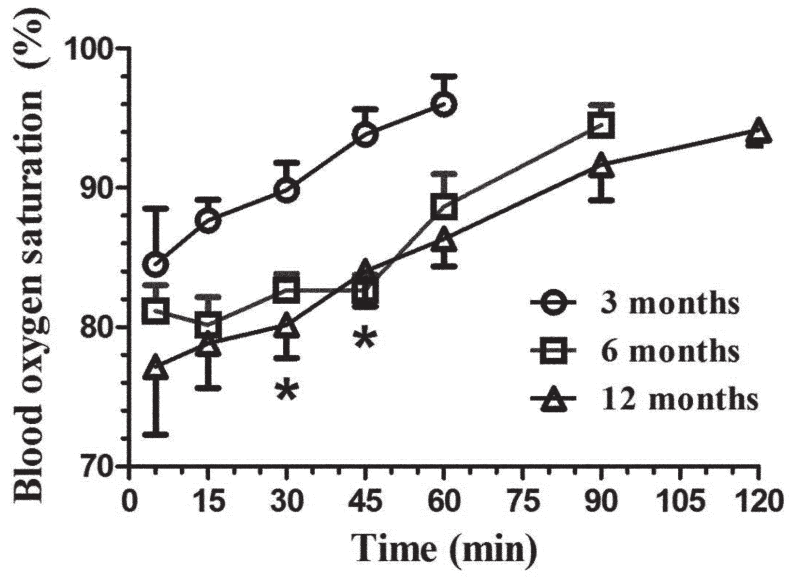

Fig. 5. Mean ( \pm SE) blood oxygen saturation (\%) in Sprague Dawley rats (n=6/age group: 3, 6, and 12 months old) following intraperitoneal administration of $125 \mathrm{mg} / \mathrm{kg}$ of ketamine and $10 \mathrm{mg} / \mathrm{kg}$ xylazine. The $\mathrm{SaO}_{2}$ was evaluated with a pulse oximeter at selected time points $(5,15,30$, and $45 \mathrm{~min}$, and $1,1.5$, and $2 \mathrm{~h}$ ), with the evaluations ending when animals had a positive withdrawal reflex. $* P<0.02$.

15 min however this decrease persisted only for 6 - and 12 -month-old rats at 15 and 30 post $\mathrm{KX}$ as well as at $60 \mathrm{~min}$ for the 12-month-old animals. Significant age group differences occurred between the 3-month-old animals and other animals ( $P<0.05$ at 30 and $45 \mathrm{~min})$.

Blood oxygen saturation (Fig. 5) varied with time for the 3- $\left(\mathrm{F}_{4,20}=3.07, P<0.05\right), 6-,\left(\mathrm{F}_{5,25}=9.78, P<0.0001\right)$ and 12-month-old rats $\left(\mathrm{F}_{6,29}=5.13, P<0.002\right)$. All groups

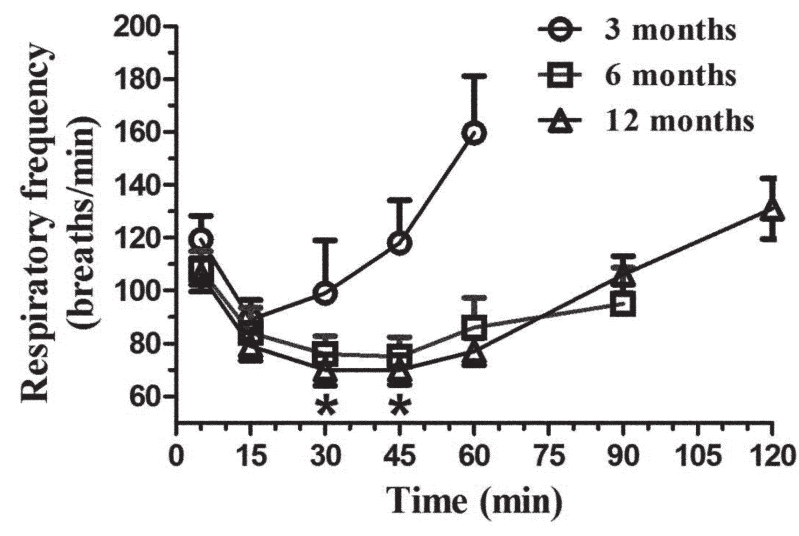

Fig. 4. Mean $( \pm \mathrm{SE})$ respiratory frequency (breaths $/ \mathrm{min}$ ) in Sprague Dawley rats (n=6/age group: 3, 6, and 12 months old) following intraperitoneal administration of $125 \mathrm{mg} / \mathrm{kg}$ of ketamine and $10 \mathrm{mg} / \mathrm{kg}$ xylazine. The respiratory frequency was evaluated at selected time points $(5,15,30$, and $45 \mathrm{~min}$, and $1,1.5$, and $2 \mathrm{~h}$ ), with the evaluations ending when animals had a positive withdrawal reflex. ${ }^{*} P<0.05$.

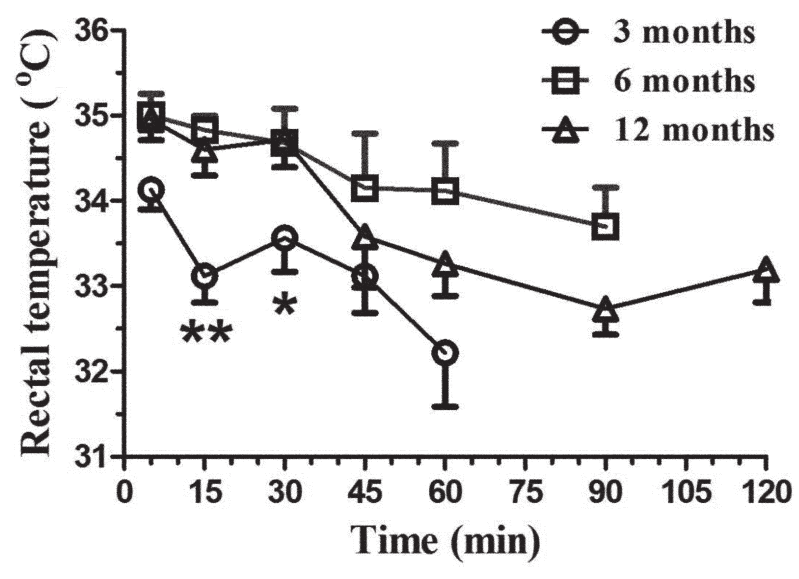

Fig. 6. Mean $( \pm \mathrm{SE})$ rectal temperature $\left({ }^{\circ} \mathrm{C}\right)$ in Sprague Dawley rats ( $\mathrm{n}=6$ /age group: 3,6 , and 12 months old) following intraperitoneal administration of $125 \mathrm{mg} / \mathrm{kg}$ of ketamine and $10 \mathrm{mg} / \mathrm{kg}$ xylazine. The rectal temperature was evaluated with a pulse oximeter at selected time points $(5,15$, 30 , and $45 \mathrm{~min}$, and $1,1.5$, and $2 \mathrm{~h}$ ), with the evaluations ending when animals had a positive withdrawal reflex. $* * P<0.001, * P<0.02$.

had significant blood oxygen saturation decreases; however, the 6- and 12-month-old animals were the most affected. Interestingly, all groups returned to near normal oxygen saturation levels upon awakening (94-96\%). Significant age group differences occurred between the 3 -month-old group and other animals at 30 and $45 \mathrm{~min}$ $(P<0.02)$.

Rectal temperature (Fig. 6) varied with time for the 
3- $\left(\mathrm{F}_{4,20}=3.11, P<0.04\right)$ and 12-month-old rats $\left(\mathrm{F}_{6,29}=5.57\right.$, $P<0.001)$ but not for the 6-month-old rats $\left(\mathrm{F}_{5,25}=1.40\right.$, $P=0.26$ ). Rectal temperature was most significantly decreased in the 12-month-old animals. No effect was observed in the 6-month-old animals; however a significant decrease was seen for the 3-month-old animals at $60 \mathrm{~min}$ post KX. Significant age group differences were found between the 3-month-old group and other animals at 15 and $30 \mathrm{~min}(P<0.001$ and 0.02 respectively).

The three-month-old rats recovered normally following anesthesia and appeared normal the next day. Although all 6-month-old rats appeared to recover normally following the anesthesia, one had to be euthanized at $9 \mathrm{~h}$ following the end of the anesthesia because it progressively deteriorated (no spontaneous movement, shallow breathing). The same observations were noted for the 12-month-old rats except that 3 animals had to be euthanized at $6 \mathrm{~h}$ following the end of the anesthesia. The remaining 6- and 12-month-old animals were considered normal at $24 \mathrm{~h}$ following anesthesia.

Figure 7 shows the macroscopic appearance of typical findings of the thoracic cage of 12-month-old affected rats. There was a moderate to significant amount of bilateral serous pleural effusion (hydrothorax). The heart appeared enlarged with a globular shape. The lungs had a diffusely glistening pleural surface (consistent with edema), with some patchy gray-red discoloration. No effusion or cardiomegaly was observed in 3- and 6-month-old rats.

The microscopic findings for lung tissue (Fig. 8) included alveolar and perivascular edemas in the 6- and 12-month-old affected rats. This was also seen in one in the 3-months-old rats, but the edema was localized to the hilum of the lung only. No or incidental histopathological findings were observed in other organs. Mild myocardial fibrosis and necrosis were observed in one 3-month-old rat and two rats of each of the other groups. The liver and kidneys were normal.

\section{Discussion}

In this study, although the duration of anesthesia increased with age, within reasonable time limits (15 to $45 \mathrm{~min}$ ), the time to recovery was very long in aged animals when considering the withdrawal and corneal reflexes as well as the time to the first voluntary movement. This was especially true for the 6- and 12-month-
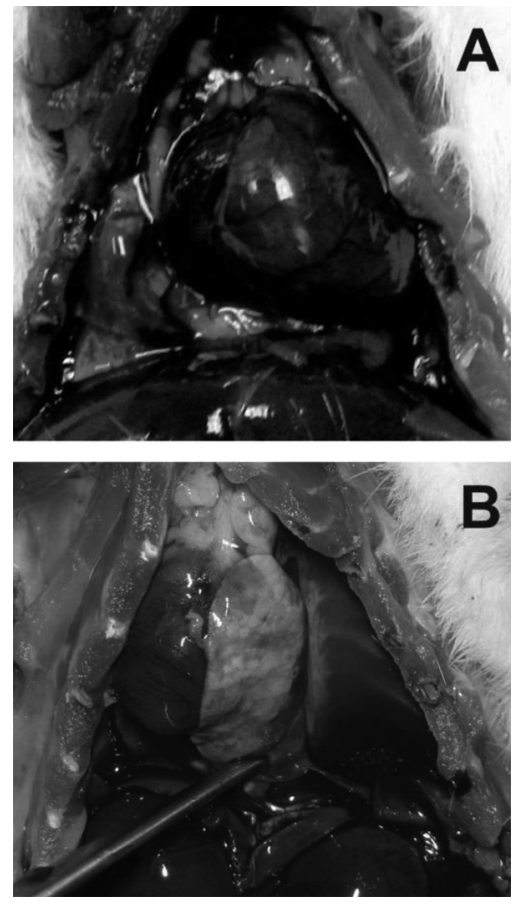

Fig. 7. Photographs of the thoracic cavity of two 12-month-old rats. A. The heart appears enlarged with a globular shape. A \& B. The lungs have a diffusely glistening pleural surface, with some patchy gray-red discoloration. A moderate to significant amount of serous pleural effusion can be seen. B. The lung is pushed to the side (with tweezers) to appreciate the amount of pleural effusion.

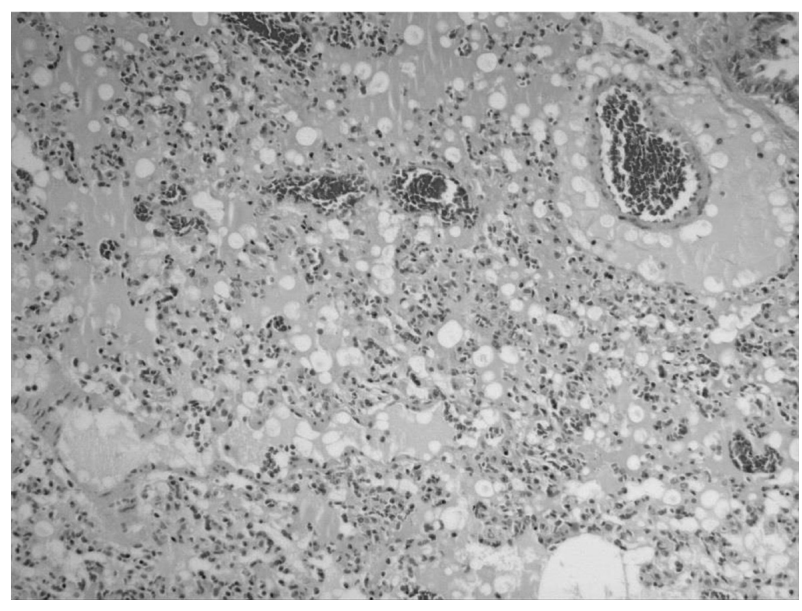

Fig. 8. Photomicrograph showing perivascular and alveolar edema seen in the 12 -month-old animals $(\times 100)$.

old rats. These animals showed a decreased cardiac frequency that did not return to baseline at the end of the observation period. Although the respiratory frequency and blood oxygen saturation were also depressed sig- 
nificantly during anesthesia, the 6- and 12-month-old animals recuperated to near normal baseline values at the end of the observation period. More importantly, one animal in the 6-month-old group, and 3 animals in the 12-month-old group, needed to be euthanized due to poor recovery form anesthesia as well as lung edema and pulmonary effusion. Therefore, these results suggest that much lower anesthetic doses need to be administered with increasing age to attain a safe level of anesthesia. In our previous study [36], we did not observe these deleterious pulmonary effects following high doses of $\mathrm{KX}$ in old animals ( $>2 \mathrm{yrs}$ ); however, the animals in the previous study were healthy aged rats (many others in the aging colony had already died of noninfectious causes), and this could possibly reflect a selection bias. Importantly, not all 18-month-old rats were equally affected (only 50\%), something we did not observe in the first study [36], which explains why we did not perform cardiac and pulmonary histopathology in these animals.

The most frequently used injectable anesthetic combination in rodents is ketamine and xylazine $[6,32]$. Ketamine has been associated with many advantages including a simple route of administration, greater margin of safety, and the possibility of being combined with other drugs [13]. Our data suggests that the margin of safety needs to be revised in light of these adverse effects. Xylazine is mainly used as a sedative and an analgesic drug [18, 19]. High doses of xylazine $(42 \mathrm{mg} /$ $\mathrm{kg}$ ) in young animals cause pulmonary edema [1-3], and this toxicity is independent of ketamine [2]. We previously showed [36] that xylazine clearance was greatly decreased in old animals, suggesting that it could attain toxic levels since greater drug exposure occurs. Both ketamine and xylazine are metabolized by the liver cytochromes P450 enzymes $[16,21]$ and changes in liver metabolism with aging could very well explain our findings [39]. Ultrastructural and biochemical changes in hepatocytes occur with aging [29] in association with changes in cytochrome P450 enzymes [26]. Future experiments in our laboratory will address the importance of hepatic metabolism of anesthetic drugs in aging rats.

Xylazine is extensively metabolized into many metabolites [23]; however, up to $70 \%$ of xylazine is eliminated in urine [24]. Ketamine is mainly transformed into an active metabolite (norketamine), and these molecules are also eliminated in urine [21]. Increased plasmatic concentrations with aging could also be due to a decrease in glomerular filtration rates, although the total number of nephrons does not seem to be altered with aging $[9,10]$. Although kidney lesions are associated with aging in Sprague Dawley rats, we did not see any anomalies even in our 12-month-old age group, and this suggests that kidney malfunction is probably not associated with microscopic changes; however, drug metabolism also occurs in the kidneys, and this could be modified with aging.

Many factors can affect the distribution of drugs such as age, sex, nutrition, environmental conditions, and diseases [17, 20, 31, 33, 35]. Aging could also affect drug metabolism due to chronic subclinical inflammation, obesity and diminished exercise [22]. Both ketamine and xylazine are lipophilic drugs that are stored in fat tissues, and this obviously alters the pharmacokinetics as fat deposits increase with age. These factors will need to be integrated into future drug metabolism studies.

In conclusion, age and associated factors have a significant effect on ketamine and xylazine anesthesia. High doses of ketamine and xylazine increased the duration of anesthesia; however, deleterious effects were mainly seen in the heart function (cardiac depression) and the lungs (pulmonary edema and effusion) of 6- and 12month-old rats. These high doses should not be recommended for anesthesia in these age groups, and if these drugs need to be used for a specific research protocol, optimization of the proper doses is strongly recommended before the study is performed. The choice of anesthetic regimen may vary with different models according to the target organ (i.e., liver or kidney) or the disease process (i.e., inflammation or cancer). Our recent findings (unpublished data) shows that if KX is used in aging animals, with uncomplicated disease processes, a dose of $80 \mathrm{mg} / \mathrm{kg}$ of ketamine and $10 \mathrm{mg} / \mathrm{kg}$ of xylazine will not affect certain organs (liver, kidney, heart, and lungs). We would therefore recommend these doses in aged Sprague Dawley rats.

\section{Acknowledgments}

The authors would like to thank Dr. Guy Beauchamp, a statistician in the Faculty of Veterinary Medicine, for the statistical analyses. This study was supported by the Fond de Développement pour la Médecine des Animaux de Laboratoire (Pascal Vachon) and the Fond du Centenaire de Faculté de Médecine Vétérinaire. 


\section{References}

1. Amouzadeh, H.R., Sangiah, S., and Qualls, C.W. Jr. 1989. Effects of some hepatic microsomal enzyme inducers and inhibitors on xylazine-ketamine anesthesia. Vet. Hum. Toxicol. 31: 532-534. [Medline]

2. Amouzadeh, H.R., Sangiah, S., Qualls, C.W. Jr., Cowell, R.L., and Mauromoustakos, A. 1991. Xylazine-induced pulmonary edema in rats. Toxicol. Appl. Pharmacol. 108: 417-427. [Medline] [CrossRef]

3. Amouzadeh, H.R., Qualls, C.W. Jr., Wyckoff, J.H. 3rd., Dzata, G.K., Sangiah, S., Mauromoustakos, A., and Stein, L.E. 1993. Biochemical and morphological alterations in xylazine-induced pulmonary edema. Toxicol. Pathol. 21: 562-571. [Medline] [CrossRef]

4. Antonaccio, M.J., Robson, R.D., and Kerwin, L. 1973. Evidence for increased vagal tone and enhancement of baroreceptor reflex activity after xylazine (2-(2,6-dimethylphenylamino)-4-H-5,6-dihydro-1,3-thiazine) in anesthestized dogs. Eur. J. Pharmacol. 23: 311-316. [Medline] [CrossRef]

5. Arras, M., Autenried, P., Rettich, A., Spaeni, D., and Rülicke, T. 2001. Optimization of intraperitoneal injection anesthesia in mice: drugs, dosages, adverse effects, and anesthesia depth. Comp. Med. 51: 443-456. [Medline]

6. Branson, K.R. 2001. Injectables anesthetics, p.213-267, In: Adams HR, editor. Veterinary Pharmacology and Therapeutics. Ames, Iowa State Press.

7. Buitrago, S., Martin, T.E., Tetens-Woodring, J., BelichaVillanueva, A., and Wilding, G.E. 2008. Safety and efficacy of various combinations of injectable anesthetics in BALB/c mice. J. Am. Assoc. Lab. Anim. Sci. 47: 11-17. [Medline]

8. Canadian Council on Animal Care1993. Guide to the care and use of experimental animals, vol 1, 2nd ed. Ottawa (Canada): Canadian Council on Animal Care.

9. Corman, B., Pratz, J., and Poujeol, P. 1985. Changes in anatomy, glomerular filtration, and solute excretion in aging rat kidney. Am. J. Physiol. 248: R282-R287. [Medline]

10. Corman, B. and Michel, J.B. 1987. Glomerular filtration, renal blood flow, and solute excretion in conscious aging rats. Am. J. Physiol. 253: R555-R560. [Medline]

11. Dittmar, M.S., Fehm, N.P., Vatankhah, B., and Horn, M. 2004. Ketamine/xylazine anesthesia for radiologic imaging of neurologically impaired rats: dose response, respiratory depression, and management of complications. Comp. Med. 54: 652-655. [Medline]

12. Flecknell, P.A.1996. Laboratory animal anesthesia. Academic Press, London.

13. Gaertner, D.J., Hallman, T.M., Hankenson, F.C., and Batchelder, M.A. 2008. Anesthesia and Analgesia for Laboratory Rodents, p.240-282, In: Fish RE, Brown MJ, Danneman PJ, Karas AZ, editors. Anesthesia and Analgesia in Laboratory Animals. San Diego, Academic Press.

14. Green, C.J., Knight, J., Precious, S., and Simpkin, S. 1981. Ketamine alone and combined with diazepam or xylazine in laboratory animals: a 10 year experience. Lab. Anim. 15: 163-170. [Medline] [CrossRef]

15. Greene, S.A. and Thurmon, J.C. 1988. Xylazine-a review of its pharmacology and use in veterinary medicine. $J$. Vet. Pharmacol. Ther. 11: 295-313. [Medline] [CrossRef]

16. Hijazi, Y. and Boulieu, R. 2002. Contribution of CYP3A4, CYP2B6, and CYP2C9 isoforms to N-demethylation of ketamine in human liver microsomes. Drug Metab. Dispos. 30: 853-858. [Medline] [CrossRef]

17. Jenkins, A.J. 2007. Toxicokinetics and Factors Affecting Pharmacokinetic Parameters, p. 21-24, In: Karch SB, editor. Pharmacokinetics and Pharmacodynamics of Abused Drugs. CRC Press.

18. Kästner, S.B. 2006. A2-agonists in sheep: a review. Vet. Anaesth. Analg. 33: 79-96. [Medline] [CrossRef]

19. Lamont, L.A., Tranquilli, W.J., and Grimm, K.A. 2000. Physiology of pain. Vet. Clin. North Am. Small Anim. Pract. 30: 703-728, v. [Medline] [CrossRef]

20. Majewski-Tiedeken, C.R., Rabin, C.R., and Siegel, S.J. 2008. Ketamine exposure in adult mice leads to increased cell death in $\mathrm{C} 3 \mathrm{H}, \mathrm{DBA} 2$ and FVB inbred mouse strains. Drug Alcohol Depend. 92: 217-227. [Medline] [CrossRef]

21. Meyer, R.E. and Fish, R.E. 2008. Pharmacology of injectable anesthetics, sedatives, and tranquilizers, p. 27-82, In: Fish RE, Brown MJ, Danneman PJ, Karas AZ, editors. Anesthesia and Analgesia in Laboratory Animals. San Diego, Academic Press.

22. Mézière, A., Paillaud, E., and Plaud, B. 2013. Anesthésie de la personne âgée. (in French). Presse Med. 42: 197-201. [Medline]

23. Mössner, L.D., Schmitz, A., Theurillat, R., Thormann, W., and Mevissen, M. 2011. Inhibition of cytochrome P450 enzymes involved in ketamine metabolism by use of liver microsomes and specific cytochrome P450 enzymes from horses, dogs, and humans. Am. J. Vet. Res. 72: 1505-1513. [Medline] [CrossRef]

24. Park Choo, H.Y. and Choi, S.O. 1991. The metabolism of xylazine in rats. Arch. Pharm. Res. 14: 346-351. [CrossRef]

25. Richardson, C.A. and Flecknell, P.A. 2005. Anaesthesia and post-operative analgesia following experimental surgery in laboratory rodents: are we making progress? Altern. Lab. Anim. 33: 119-127. [Medline]

26. Rikans, L.E. and Notley, B.A. 1982. Age-related changes in hepatic microsomal drug metabolism are substrate selective. J. Pharmacol. Exp. Ther. 220: 574-578. [Medline]

27. Salonen, J.S.1992. Chemistry and pharmacokinetics of the alpha2-adrenoreceptor agonist, p.191-200, In: Short CE, Van Poznak A, editors. Animal Pain. New York, Churchill Livingstone.

28. Schmitt, H., Fournadjiev, G., and Schmitt, H. 1970. Central and peripheral effects of 2-(2,6-dimethylphenylamino)4-H-5,6-dihydro-1,3-thiazin (Bayer 1470) on the sympathetic system. Eur. J. Pharmacol. 10: 230-238. [Medline] [CrossRef]

29. Schmucker, D.L. 1990. Hepatocyte fine structure during maturation and senescence. J. Electron Microsc. Tech. 14: 106-125. [Medline] [CrossRef]

30. Smith, D.J., Pekoe, G.M., Martin, L.L., and Coalgate, B. 1980. The interaction of ketamine with the opiate receptor. Life Sci. 26: 789-795. [Medline] [CrossRef]

31. Song, G., Wu, H., Yoshino, K., and Zamboni, W.C. 2012. 
Factors affecting the pharmacokinetics and pharmacodynamics of liposomal drugs. J. Liposome Res. 22: 177-192. [Medline] [CrossRef]

32. Stokes, E.L., Flecknell, P.A., and Richardson, C.A. 2009. Reported analgesic and anaesthetic administration to rodents undergoing experimental surgical procedures. Lab. Anim. 43: 149-154. [Medline] [CrossRef]

33. Struck, M.B., Andrutis, K.A., Ramirez, H.E., and Battles, A.H. 2011. Effect of a short-term fast on ketamine-xylazine anesthesia in rats. J. Am. Assoc. Lab. Anim. Sci. 50: 344-348. [Medline]

34. Schwenke, D.O. and Cragg, P.A. 2004. Comparison of the depressive effects of four anesthetic regimens on ventilatory and cardiovascular variables in the guinea pig. Comp. Med. 54: 77-85. [Medline]

35. Veilleux-Lemieux, D., Beaudry, F., Hélie, P., and Vachon, P. 2012. Effects of endotoxemia on the pharmacodynamics and pharmacokinetics of ketamine and xylazine anesthesia in Sprague-Dawley rats. Vet. Med. Res. Rep. 3: 99-109.

36. Veilleux-Lemieux, D., Castel, A., Carrier, D., Beaudry, F., and Vachon, P. 2013. Pharmacokinetics of ketamine and xylazine in young and old Sprague-Dawley rats. J. Am. Assoc. Lab. Anim. Sci. 52: 567-570. [Medline]

37. Velísková, J., Velísek, L., Mares, P., and Rokyta, R. 1990. Ketamine suppresses both bicuculline- and picrotoxininduced generalized tonic-clonic seizures during ontogenesis. Pharmacol. Biochem. Behav. 37: 667-674. [Medline] [CrossRef]

38. Waterman, A.E. and Livingston, A. 1978. Effects of age and sex on ketamine anaesthesia in the rat. Br. J. Anaesth. 50: 885-889. [Medline] [CrossRef]

39. Wauthier, V., Verbeeck, R.K., and Buc Calderon, P. 2004. Age-related changes in the protein and mRNA levels of CYP2E1 and CYP3A isoforms as well as in their hepatic activities in Wistar rats. What role for oxidative stress? Arch. Toxicol. 78: 131-138. [Medline] [CrossRef]

40. White, P.F., Way, W.L., and Trevor, A.J. 1982. Ketamineits pharmacology and therapeutic uses. Anesthesiology 56: 119-136. [Medline] [CrossRef] 